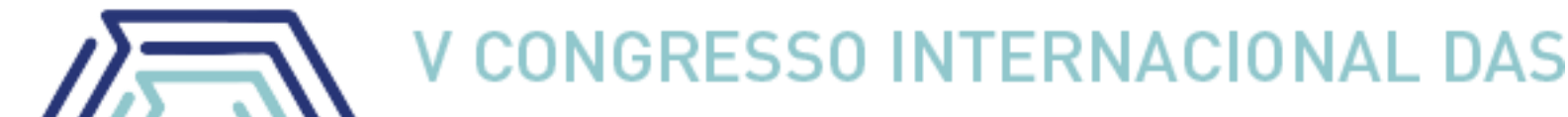 LICENCIATURAS COINTER - PDVL 2018
}

\section{OLHARES DIVERSOS DO SABER INSTITUÍDO ATRAVÉS DO PROJETO INTEGRADOR}

\section{MISCELLANEOUS VIEWS OF KNOWLEDGE ESTABLISHED THROUGH THE INTEGRATING PROJECT}

Apresentação: Relato de Experiência

Cleiton Pedrosa de Sales ${ }^{1}$; Isabel Bezerra Lima ${ }^{2}$; Teresinha Vilani Vasconcelos de Lima ${ }^{3}$

DOI: https://doi.org/10.31692/2358-9728.VCOINTERPDVL.2018.00306

\section{Introdução}

O projeto integrador é um componente curricular, oferecido nos cursos de licenciatura do Instituto Federal do Piauí - IFPI desde 2016, e segundo os Projetos Pedagógicos dos cursos de licenciatura, o mesmo é desenvolvido na primeira metade do curso e tem como objetivo relacionar teoria e prática em uma perspectiva de ensino e fortalecer a formação pedagógica juntamente com fundamentos técnico-científicos e envolvendo as disciplinas do semestre em curso e/ou de semestres anteriores. A integração realizada nos projetos integradores adota um ensino voltado à integração dos saberes, em uma perspectiva de ações interdisciplinares. Pela intensidade das trocas entre os especialistas e pelo grau de interação real das disciplinas no interior de um mesmo projeto de ensino, Japiassu (1976) define interdisciplinaridade.

O projeto integrador desenvolvido nos cursos de licenciatura do IFPI é uma estratégia utilizada na formação inicial docente dentro de um espaço interdisciplinar, que potencializa a formação inicial. A interdisciplinaridade é um movimento que procura quebrar um método de formação tradicional, onde a maior parte do que é ensinado é em sala de aula, deixando a parte a aplicação na realidade, o projeto integrador nesse sentido procura romper com essa metodologia de ensino estanque nos cursos de licenciatura e estreitar uma formação extensionista como podemos perceber no projeto desenvolvido pelo I módulo do Curso de

\footnotetext{
${ }^{1}$ Licenciatura em Matemática, Instituto Federal de Educação, Ciência e Tecnologia do Piauí - Campus Teresina Central, cleitonsales1995@gmail.com

${ }^{2}$ Licenciatura em Matemática, Instituto Federal de Educação, Ciência e Tecnologia do Piauí - Campus Teresina Central, isabelblima1@gmail.com

${ }^{3}$ Especialista em Supervisão Escolar, Instituto Federal de Educação, Ciência e Tecnologia do Piauí - Campus Teresina Central, vilani@ifpi.edu.br
} 
Licenciatura em Matemática no primeiro semestre de 2016.

\section{Relato de Experiência}

No processo de formação interdisciplinar com vistas à contextualização de saberes, o processo de desenvolvimento dos Projetos Integradores envolve trabalho docente e discente com atividades de natureza diversa. Nesse sentido, o Projeto Integrador I, do curso de Licenciatura em Matemática do IFPI - Campus Teresina em seu I módulo teve em seu desenvolvimento a princípio, a apresentação aos graduandos o perfil, objetivos das disciplinas do semestre, tema do Projeto Integrador I escolhidos pelos professores orientadores envolvidos e a proposta conceitual e metodológica.

Com o tema do Projeto Integrador I - Matemática no cotidiano e cultura popular: Educação financeira na prática: orçamento na construção de uma casa popular, o objetivo foi desenvolver um estudo multidisciplinar no Conjunto Habitacional Jacinta AndradeTeresina(PI), com atividades na perspectiva interdisciplinar com os graduandos do I módulo com a comunidade externa, buscando aplicar conhecimentos adquiridos em sala de aula com a realidade, conhecimentos previamente apresentados como cálculo de áreas, volumes, distância entre pontos, matemática financeira e etc.

Para o desenvolvimento das atividades proposta ocorria: reuniões periódicas, discussões das atividades, metodologias de execução e cronograma de atividades dos envolvidos para desenvolvimento do estudo Projeto Integrador I.

Após cada encontro com os professores era realizado: socialização e discussão dos encaminhamentos das reuniões como: atividades, metodologias de execução e cronograma com os graduandos. Como atividades foram: Pesquisas orientadas sobre Educação Financeira; Seminário Temático; leitura e pesquisas de textos sobre o Programa Minha Casa Minha Vida; visita técnica ao Conjunto Habitacional Jacinta Andrade Teresina - PI e a escola municipal do conjunto, para conhecimento e levantamento de dados; trabalhos em grupos e individuais para compilação e interpretação dos dados coletados nas visitas técnicas e confecção dos banners e panfletos.

Para socialização foi planejado um Seminário de Socialização das experiências do Projeto Integrador I - Matemática no cotidiano e cultura popular: Educação financeira na prática. 
Imagem 1: Reunião com a equipe gestora e corpo docente da escola municipal do conjunto. Fonte Própria.

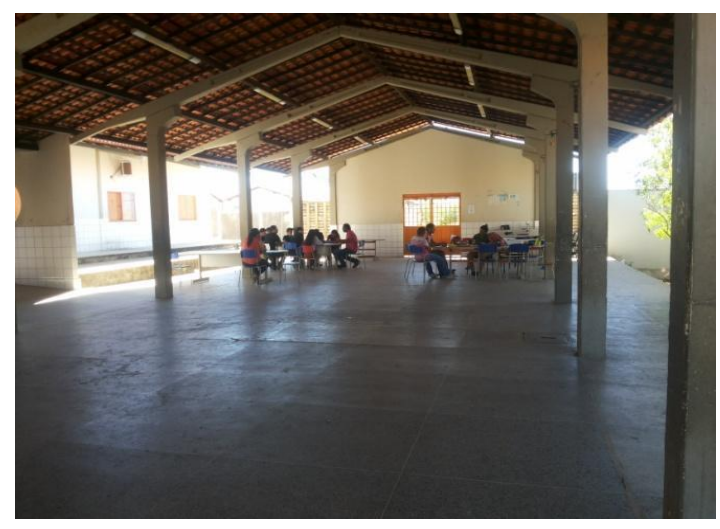

Imagem 3: Palestra: Educação financeira e construção de uma casa popular. Fonte: Própria.

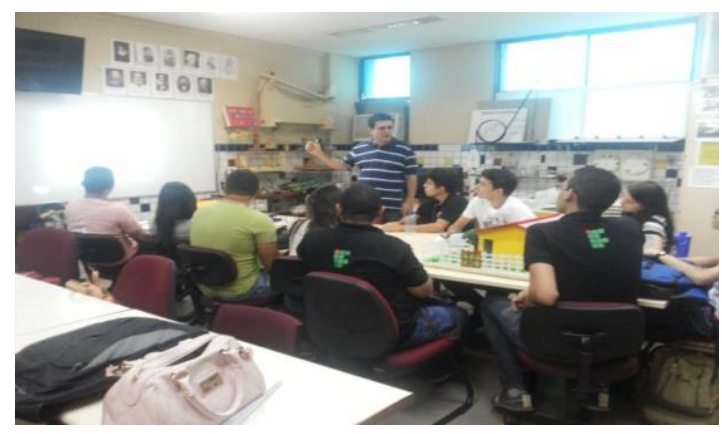

Imagem 2: Atividade de medição da casa popular para construção de maquete e cálculo do material necessário para construção de uma casa popular. Fonte Própria.

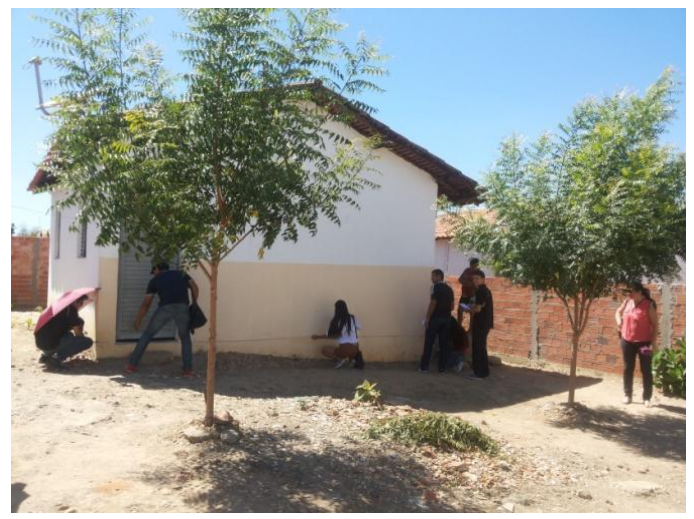

Imagem 4: Socialização dos recursos didáticos concretos para o ensino de matemática.

Fonte: Própria.

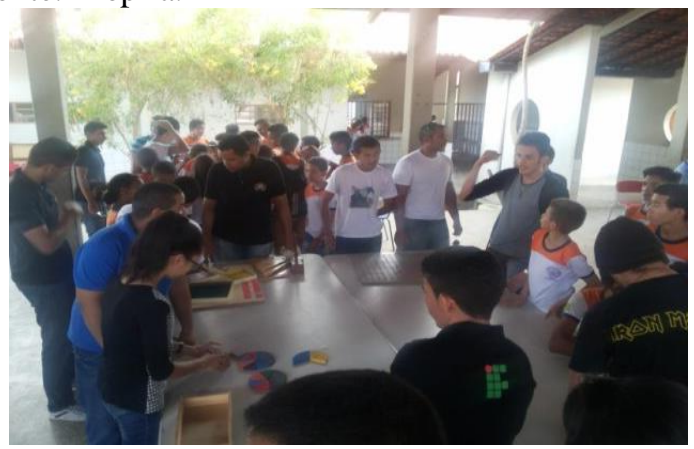

A Lei de Diretrizes e Bases da Educação Nacional (LDBEN) 9.394/1996 aborda as orientações curriculares e pronuncia sobre a utilização da contextualização como proposta relevante para a educação, além de afirmar que, a contextualização/descontextualização que o aluno constrói conhecimento com significado, nisso se identificando com as situações que lhe são apresentadas, seja em seu contexto escolar, seja no exercício de sua plena cidadania. (BRASIL, 2006, p. 83).

Percebe-se a importância do planejamento e do comprometimento do docente para com o ensinar ressaltada no documento. Observa-se, durante a proposta da atividade executada com os discentes, um grande aprendizado sobre didática, metodologia, postura profissional e também o quanto se faz essencial os alunos receberem a orientação adequada para executar uma atividade. $\mathrm{O}$ acompanhamento na prática e a conexão entre as disciplinas ofertadas na matriz curricular e a articulação com a escola campo de atuação, pode agregar a uma contextualização concreta, em locos, foi relatado pelos graduandos que houve uma 
aprendizagem muito mais significativa e que essa metodologia agregou conhecimento a eles, então se a mesma for colocada na educação básica, teria se estudantes criativos e cada vez mais investigativos de sua própria realidade. As atividades práticas articuladas entre os sistemas de ensino e instituições educativas de modo a propiciar vivências nas diferentes áreas do campo educacional, assegurando aprofundamento e diversificação de estudos, experiências e utilização de recursos pedagógicos;

Para socialização do projeto foi planejado e realizado um Seminário de Socialização das experiências do Projeto Integrador I - Matemática no cotidiano e cultura popular: Educação financeira na prática, em que também serviu para avaliar todo o processo formativo.

\section{Considerações}

A experiência do projeto integrador logo no início do curso foi ao mesmo tempo enriquecedora pelo fato de proporcionar uma nova visão com relação ao campo de atuação do professor, e também chocante por possibilitar a apresentação de uma comunidade escolar muito carente desse tipo de prática. Os graduandos do I módulo do curso de Licenciatura em Matemática do IFPI - Campus Teresina Central, em suas falas relataram na roda de conversa, a possibilidade de um amadurecimento com relação a ser professor.

No decorrer do projeto, tivemos que lidar com várias dificuldades, a distância, a falta de arborização urbana, os altos índices de periculosidade em torno da escola campo, fatores que tivemos que levar em consideração para o sucesso desse projeto. Com enorme sensação de satisfação, de dever cumprido, e as experiências vivenciadas, serviram como alicerce para modelar nossas perspectivas como professores em formação, experiências essas que usaremos para nortear nossa carreira profissional, buscando assim, se sensibilizar para/com o aluno em situação de fragilidade, aceitando que as diferenças sociais são reais e passíveis de intervenções.

\section{Referências}

BRASIL. Lei no 9.394, de 20 de dezembro de 1996. Diretrizes e Bases da Educação Nacional. Brasília, DF. 1996.

BRASIL. Resolução $\mathbf{n}^{\circ}$ 2, de $\mathbf{1}^{\mathbf{0}}$ de julho de 2015. Diretrizes Curriculares Nacionais para a formação inicial em nível superior (cursos de licenciatura, cursos de formação pedagógica para graduados e cursos de segunda licenciatura) e para a formação continuada. Brasília, DF.

JAPIASSU, H. Interdisciplinaridade e patologia do saber. Rio de Janeiro: Imago, 1976. 
IFPI. Projeto Político Pedagógico do Instituto Federal de Educação, Ciência e Tecnologia do Piauí. Campus Teresina Central. 2015. 